\title{
The role of ferrous clays in the interpretation of wettability - a case study
}

\author{
Velazco M.A ${ }^{1, *}$, Bruce $\mathrm{A}^{1}$., Ferris $\mathrm{M}^{1}$, Reed $\mathrm{J}^{1}$., Kandasamy $\mathrm{R}^{1}$. \\ ${ }^{1}$ Lloyd's Register Energy Consultancy, Rock Properties Group, Aberdeen, UK
}

\begin{abstract}
Clean sandstone, with minimal clay content, is expected to be strongly water wet once the rock has been through an effective cleaning process. Even samples containing significant clay minerals are usually expected to be water wet after appropriate cleaning. However, tests carried out on core samples from Fields in three different global locations show mixed indices, even for clean state samples where no aging with crude oil has taken place. A few hypotheses for this behaviour considered herein are: whether the cleaning method was adequate, whether wettability was altered by an external factor, or if wettability was due to mineral composition. This paper presents the results obtained from wettability studies on fresh, clean and restored state core plug samples from three different Fields. Wettability indices were obtained by using the combined Amott-USBM method. Petrography was performed on sample end-trims to investigate the possible presence of halite or barite in the clean state samples, thought to be from drilling fluid infiltration, which should have been removed by the methanol cleaning cycle. This showed no organic material or salt (halite), negating wetting change from inefficient cleaning. From a reactive clays [1] model perspective, these rock samples are considered clean-sand (i.e. illite/ smectites- as total clay content), determined by XRD analysis, are lower than $10 \%$. SEM and XRD results showed the presence of grain-coating chlorite in one sample set and glauconite grains in the others. Only once the unusual wettability indices were obtained was the grain-coating chlorite identified as chamosite by SEM/EDX, which is an iron-rich form of chlorite. The presence of chamosite or glauconite appears to influence the wetting tendency. In summary, USBM vs Amott wettability indices of the analysed samples are consistent between both methods, showing a mixed to oil-wet tendency for all samples where chamosite was identified, regardless of the initial test condition. Samples with glauconite appeared to be more mixed wet after wettability restoration. The results suggest that iron rich clay/mineral content is the main contributor to the oil wet tendency of the evaluated rocks.
\end{abstract}

\section{Introduction}

Wettability is an important rock-fluid property that controls how fluids are distributed and flow within porous media [1]. It is the result of a complex interaction of forces, related to the reservoir fluid system and the rock composition, and has a major impact on capillary behaviour, core electrical measurements [2, 3, 4], relative permeability tests and residual saturations [5]. Lab testing requires representative wettability conditions to ensure the results are representative for input to reservoir simulation.

Anderson (Part 1) [2] presented in his paper the variables that control wettability: oil type and composition, brine chemistry and grain/mineral type. The general assumption, for conventional reservoirs, is that before hydrocarbons migrated into the reservoir, the rock was water wet because the grains were only in contact

* corresponding author: Maria.Velazco@lr.org with water. As oil accumulated at the top of the reservoir, filling much of the porous media, adsorption of polar compounds (like resins and asphaltenes, the natural surfactants of the oil) can induce wettability change, away from water wet. In clastic reservoirs, clay minerals are present in variable amounts and will influence the wettability tendency. In oil saturated sandstones kaolinites are preferentially wetted by oil [6]; however, kaolinite changes wettability depending upon $\mathrm{pH}$ [7], while illite and other clays are essentially wetted by water. Bantignies et al. [8] found that the wettability contrasts between illite and kaolinite are related to structural differences between the two clay types. Knowledge about the effect of iron-rich minerals such as glauconite [9] and chamosite $[10,11]$ on the wettability in the literature is limited.

There remains an industry debate about the best approach for considering wetting conditions during core analysis. Some companies/professionals would recommend the use of fresh (or native, or "as received") 
state core samples, with protocols designed to maintain the wetting and saturation conditions of the core from reservoir to the lab. However, native wettability of reservoir core samples can be affected and altered by the coring and core handling processes: during coring and core recovery, through invasion of and contact with, drilling mud components/additives; pressure and temperature losses; and potential oxidation of oil and/or rock components. Probably the predominant, current recommended industry approach [1] is to restore the wettability by appropriate cleaning (to mimic prehydrocarbon migration, water-wet conditions), establish representative formation water saturation, introduce representative reservoir oil and apply pressure and temperature for "sufficient" time. Both techniques have pros and cons and require deliberation of what might be the most appropriate approach for a particular reservoir being studied, based on the core material and fluids available to testing and the contracted laboratory equipment limitations.

In this paper, we will provide the results of wettability studies carried out on fresh state (FS), clean state (CS) and restored state (RS) core plug samples from three oil Fields, henceforth named A, B and C, in three global locations, together with mineralogical characterisation data using x-ray diffraction (XRD), scanning electron microscopy (SEM) and thin section analysis (TSA).

\section{2 wettability test methods and results}

Combined Amott-USBM wettability tests were performed on core samples from the three sandstone reservoirs under the three wetting states.

Figure 1 shows a schematic illustration of the preparation processes used for these different wetting states. For simplicity, the interpretation of Amott and USBM wettability indices were performed using the scale presented in Table 1.
Table 1. Interpretation of Amott and USBM wettability index

\begin{tabular}{|l|l|c|c|}
\hline \multirow{2}{*}{ Wettability indices } & \multicolumn{3}{|c|}{$\begin{array}{c}\text { Interpretation of } \\
\text { wettability indices }\end{array}$} \\
\cline { 2 - 4 } & $\begin{array}{c}\text { Water- } \\
\text { Wet }\end{array}$ & $\begin{array}{c}\text { Neu } \\
\text { tral }\end{array}$ & Oil-Wet \\
\hline $\begin{array}{l}\text { Relative Displacement } \\
\text { Index (Amott-Harvey) }\end{array}$ & $\begin{array}{l}\text { Positive } \\
\text { value } \\
\text { Positive } \\
\text { value }\end{array}$ & $\begin{array}{c}\text { Negative } \\
\text { value } \\
\text { Negative } \\
\text { value }\end{array}$ \\
\hline
\end{tabular}

FS samples were initially flushed at 200 psi back pressure with mineral oil to remove gas and to displace dead crude oil to a controlled laboratory mineral oil. To avoid potential clay damage, clean and restored state samples were prepared by warm constant immersion cleaning, using a chloroform and methanol azeotropic mixture as the solvent, and humidity oven dried $\left(60^{\circ} \mathrm{C}\right.$ and $\left.40 \% \mathrm{RH}\right)$ to constant weight. Basic properties: air permeability (Ka) and porosity $(\Phi)$ of the samples are presented in Table 2. Ka was measured by steady state method at 400 psi and $\Phi$ was calculated by Helium grain density and Helium pore volume. Ka and $\Phi$ of FS samples were measured after completion of the wettability tests. One of the FS samples from Field B failed when measuring the air permeability. Thus, it was only possible to measure porosity allowing this the wettability calculations. Once clean and dried, the samples for CS and RS testing were saturated with their corresponding synthetic formation water (SFW in $\mathrm{NaCl}$ equivalent, Field A:46000 ppm, Field B: 190000 ppm, Field C:35000 ppm) were desaturated to $\mathrm{Sw}_{\mathrm{i}}$ using synthetic lab oil (Isopar-L) by centrifuge in lower permeability samples $(\mathrm{Ka}<123 \mathrm{mD})$ and by porous plate in high permeability samples $(\mathrm{Ka}>370 \mathrm{mD})$. CS samples continued directly to spontaneous imbibition without ageing, and RS samples were flooded with their corresponding crude oil and aged at elevated temperature and nominal pore pressure (200 psi of back pressure) for 40 days.

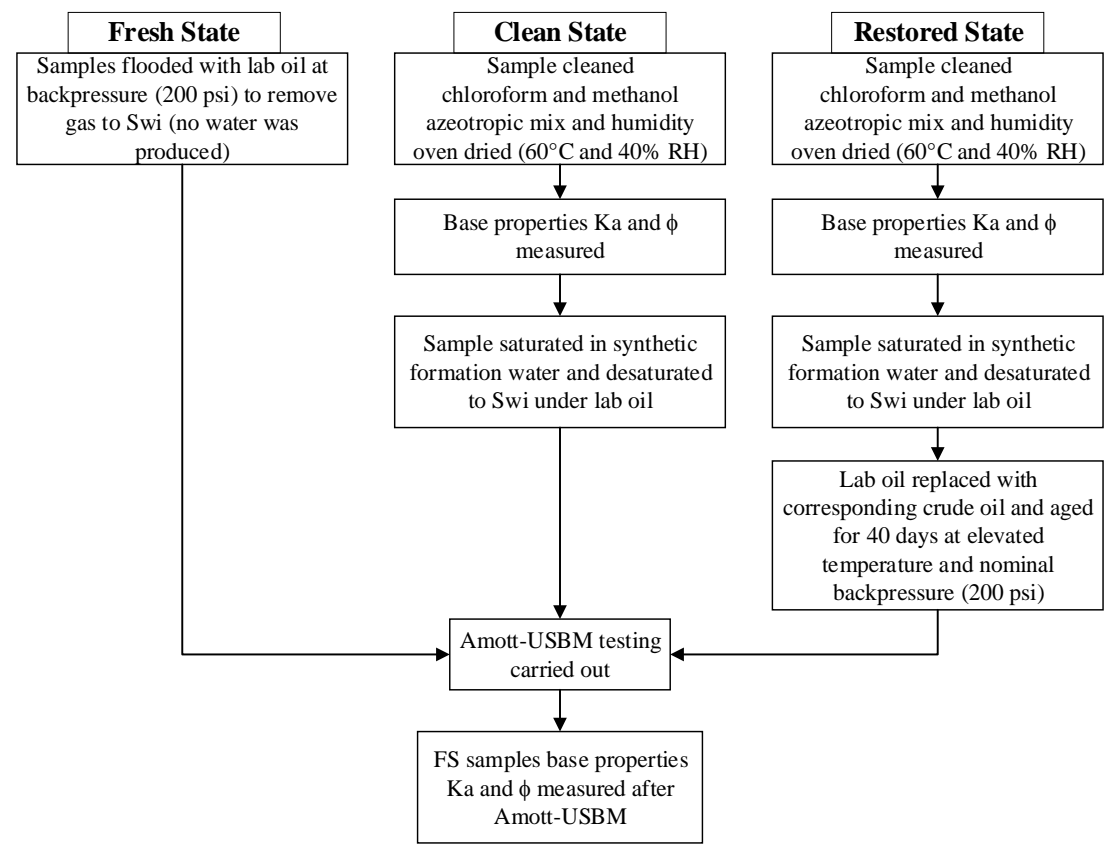

Fig. 1. Illustration of the sample preparation process for the wettability study 
Table 2. Sample properties

\begin{tabular}{|c|c|c|c|c|c|}
\hline Field & Region & Sample & State & $\begin{array}{l}\text { Air Permeability } \\
\text { (Ka) Range (mD) }\end{array}$ & $\begin{array}{c}\text { Porosity (Ф) } \\
\text { Range }(\%)\end{array}$ \\
\hline \multirow{8}{*}{ A } & \multirow{8}{*}{ Northern Europe } & $1 \mathrm{~A}$ & Clean & \multirow{8}{*}{$93-123$} & \multirow{8}{*}{$30-32$} \\
\hline & & $2 \mathrm{~A}$ & Clean & & \\
\hline & & $3 \mathrm{~A}$ & Restored & & \\
\hline & & $4 \mathrm{~A}$ & Restored & & \\
\hline & & $5 \mathrm{~A}$ & Restored & & \\
\hline & & $6 \mathrm{~A}$ & Restored & & \\
\hline & & $7 \mathrm{~A}$ & Fresh & & \\
\hline & & $8 \mathrm{~A}$ & Fresh & & \\
\hline \multirow{7}{*}{$\mathrm{B}$} & \multirow{7}{*}{ Central Europe } & $1 \mathrm{~B}$ & Clean & \multirow{7}{*}{$370-8600$} & \multirow{7}{*}{$25-32$} \\
\hline & & $2 \mathrm{~B}$ & Clean & & \\
\hline & & $3 \mathrm{~B}$ & Restored & & \\
\hline & & $4 \mathrm{~B}$ & Restored & & \\
\hline & & $5 B$ & Restored & & \\
\hline & & $6 \mathrm{~B}$ & Fresh & & \\
\hline & & $7 \mathrm{~B}$ & Fresh & & \\
\hline $\mathrm{C}$ & Asia Pacific & $1 \mathrm{C}$ to $10 \mathrm{C}$ (10 samples) & Clean & $8-47$ & $17-18$ \\
\hline
\end{tabular}

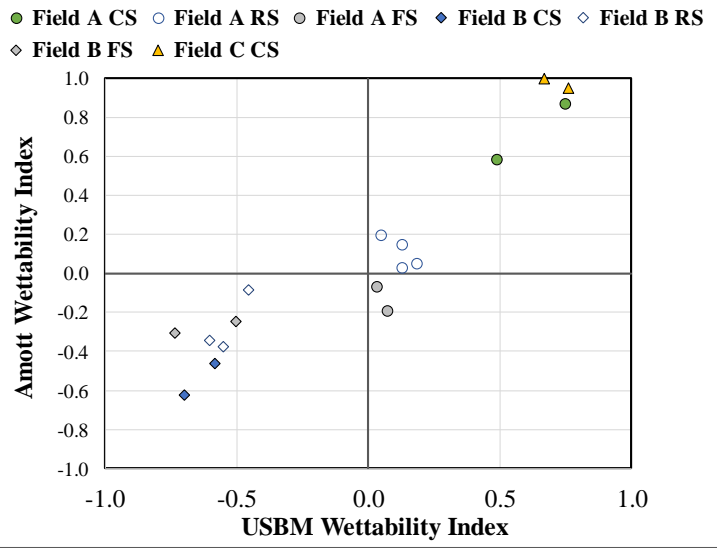

Fig. 2. Amott Wettability index (AWI) as function of USBM wettability index (USBM WI) by test state condition. CS-Clean State, RS-Restored State and FS-Fresh State

Combined Amott-USBM wettability tests were performed using synthetic lab oil for the oil drive part and synthetic formation water (for the respective field) for the water drive part on all samples from Fields A and B, and in two samples (out of ten) from Field C. Figure 2 presents the results of these tests, showing a relatively good consistency between the two methods for all samples under study. The range of USBM index results per Field are also presented in Table 3 . Average clean state primary imbibition and secondary drainage USBM curves per Field, converted into J-Functions $\left(\mathrm{J}\left(\mathrm{S}_{\mathrm{w}}\right)=\right.$ $\left.\frac{0.2166 \mathrm{Pc} \sqrt{\mathrm{Ka} / \varnothing})}{\sigma \cos \theta}\right)$, where $\sigma($ dynes $/ \mathrm{cm})$ is the surface tension and $\theta$ (degrees) is the contact angle, are presented in Figure 3 . The average capillary pressure for the primary imbibition and secondary drainage cycles of CS samples for Fields A, B and C are presented in Figure 4 (a) to (c). USBM [12] wettability index is obtained by calculating the natural $\log$ of the ratio of area under the secondary drainage (area A1 - blue) and imbibition curves (area A2
- red) as shown in Figure 4 (d), hence $\mathrm{I}_{\mathrm{USBM}}=\ln (\mathrm{A} 1 / \mathrm{A} 2)$. The imbibition curves do not exhibit expected behaviour for a clean state water wet core for Fields B and C. Strong water wetness (expected from clean state samples) should produce USBM index values greater than +0.5 (often close to or greater than +1.0 ). USBM wettability indices results, summarised in Table 3, for Field B samples are between -0.5 and -0.6 , indicating an oil wet tendency. Data from Field C samples produce values between +0.08 and +0.16 on most of the samples (8), with only two samples appearing to have strong water wet indices.

Table 3. USBM wettability index range of clean state samples from Fields A, B and C

\begin{tabular}{|c|c|c|c|}
\hline Field & $\begin{array}{c}\text { Amott } \\
\text { Wettability } \\
\text { Index }\end{array}$ & $\begin{array}{c}\text { UBSM } \\
\text { Wettability } \\
\text { Index }\end{array}$ & $\begin{array}{c}\text { Wettability } \\
\text { tendency }\end{array}$ \\
\hline A & +0.5 to +0.74 & +0.5 to +0.8 & Water wet \\
\hline B & -0.7 to -0.6 & -0.5 and -0.6 & Oil wet \\
\hline C & Not performed & +.08 to +0.16 & Mixed wet \\
\hline
\end{tabular}

Amott and USBM wettability indices as a function of initial water saturation $\left(\mathrm{Sw}_{\mathrm{i}}\right)$ for all states $(\mathrm{CS}, \mathrm{FS}$ and $\mathrm{RS}$ ) are presented in Figure 5. This figure shows that samples with $\mathrm{Sw}_{\mathrm{i}}$ lower than 0.2 exhibit a clear oil wet tendency whereas higher $\mathrm{Sw}_{\mathrm{i}}$ values appear to be more scattered in the mixed to water wet region. Wettability tests on restored state and fresh state samples show a mixed to oil wetting tendency in most of the samples.

Clean state wettability tests were performed to quality control if the cleaning method was effective in removing all hydrocarbon contaminants from the samples and resulted in a strongly water wet tendency in Field A, but not in Field B. Field C samples have a mixed to water wet behaviour. Inefficient cleaning time was ruled out as there were no fluorescence in the samples and petrography analyses did not show high halite, barite or organic content. Any halite present in a clean state sample is 
believed to be from the coring fluids and should have been removed by the methanol in the cleaning process [13].

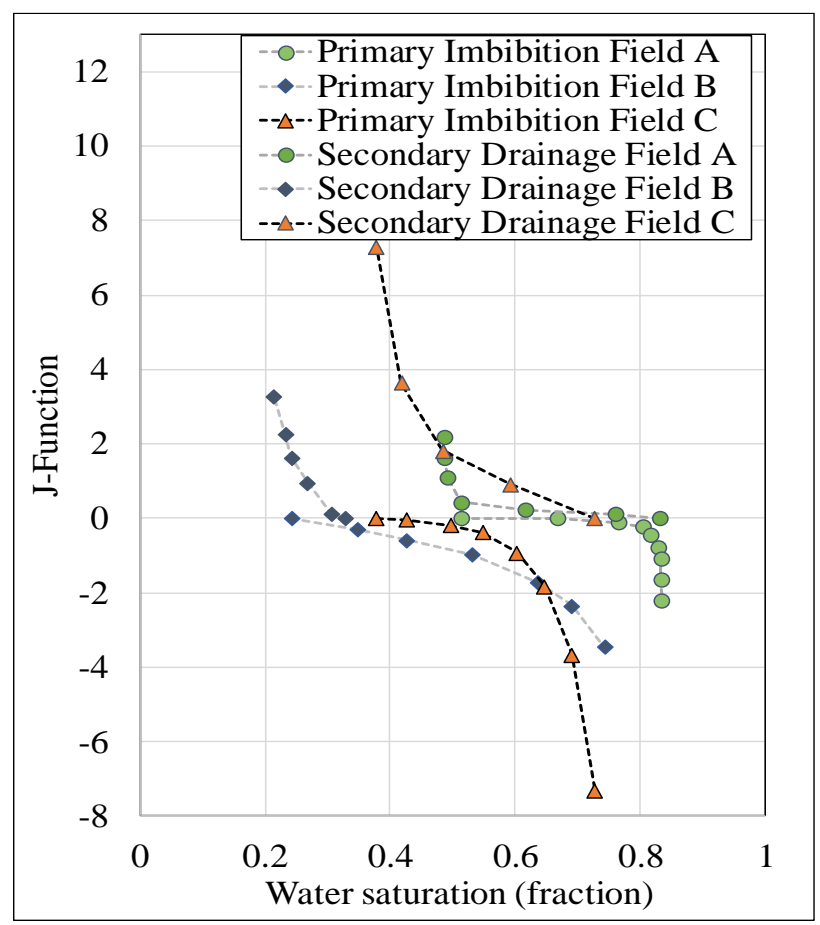

Figure 3. Clean state average (per Field) primary drainage and primary imbibition capillary pressure curves, converted to JFunctions - One average curve per field is presented only

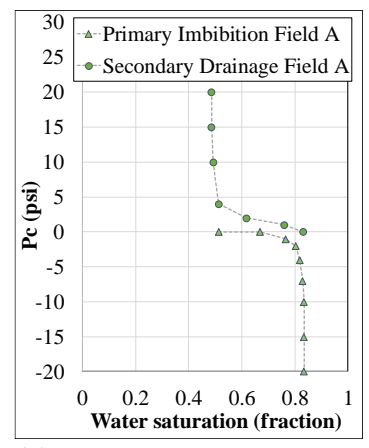

(a)

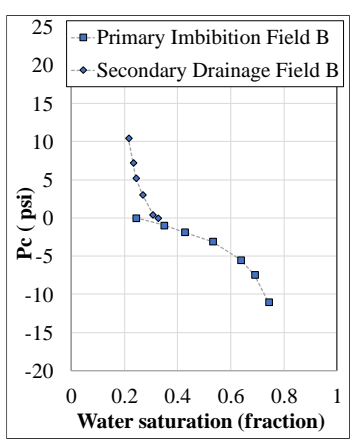

(b)

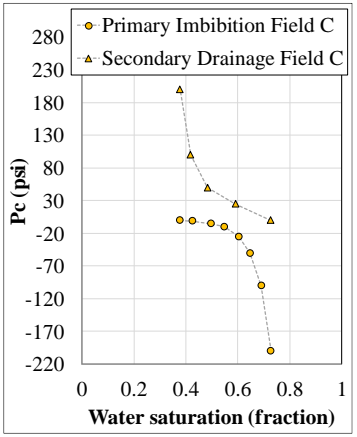

(c)

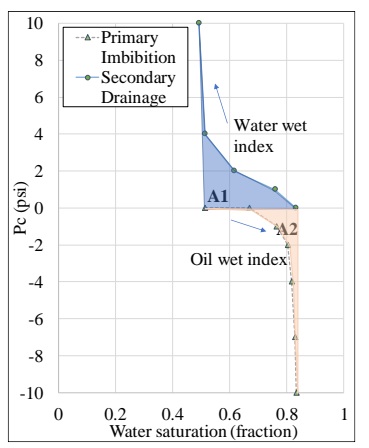

(d)
Figure 4. Capillary Pressure - primary imbibition and secondary drainage (a) Field A, (b) Field B and (c) Field C. (d)

Different coring fluid systems were used across the Fields: oil-based mud (OBM) in Fields A and B, and water-based mud (WBM) for Field C. No tracer analysis was performed in Field $\mathrm{A}$ for mud invasion. In order to investigate mud filtrate invasion into the core of Field B, the water phase of the OBM was doped with deuterium oxide $\left({ }^{2} \mathrm{H}\right)$. Several mud samples were collected at the wellsite in conjunction with Dean-Stark (DS) plugs. The mud samples and the wellsite core plugs underwent DS analyses. Tracer analysis was carried out on the distilled water collected from the DS plugs and mud samples. The mean concentration of ${ }^{2} \mathrm{H}$ in the mud was around $620{ }^{2} \mathrm{H}$ ppm and $150{ }^{2} \mathrm{H}$ ppm on the DS showing no evidence of invasion, which eliminated the influence of coring fluid in irreversibly altering wettability in samples from Field B. Water-based mud (WBM) systems historically have contained less additives. However, some modern WBM fluids may contain surfactant/emulsifying agent additives, thus increasing the potential for alteration of wettability. The use of additives in the WBM is uncertain and no tracer analysis was performed on cores from Field C.
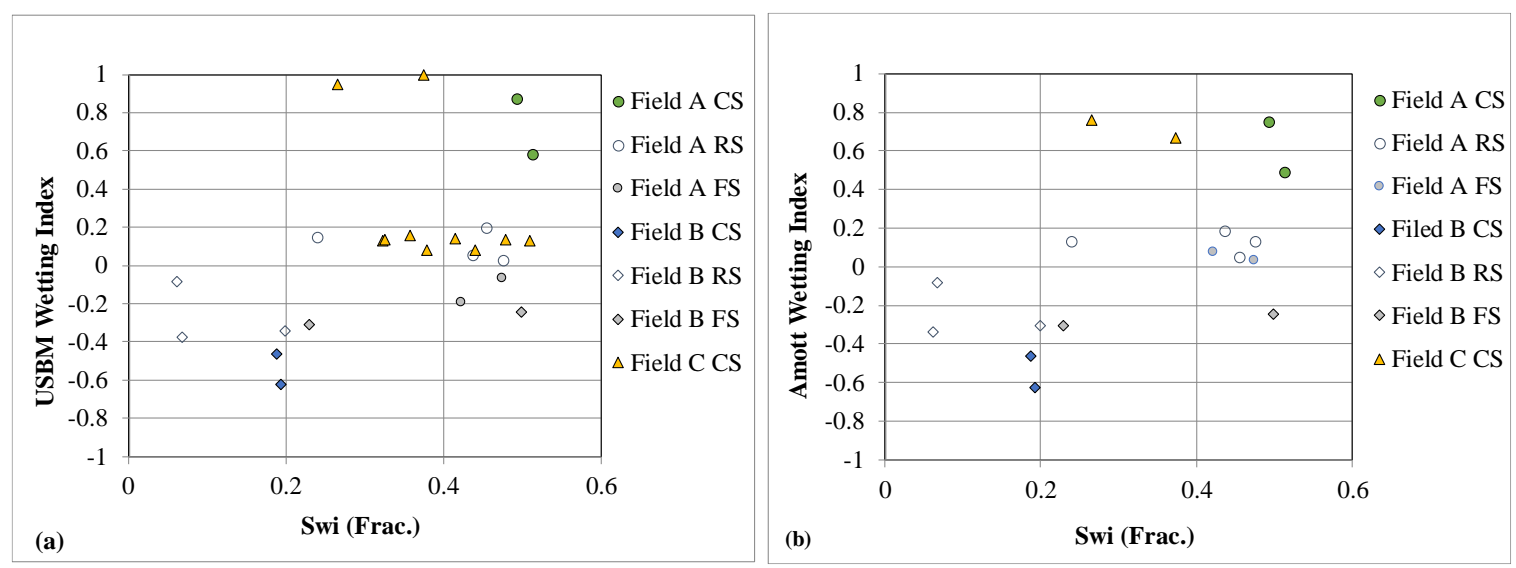

Fig. 5. (a) USBM wettability index and (b) Amott Wettability Index as function of initial water saturation (Swi) 
Table 4. XRD analyses -summary of clay content average (Avg.) values by Field

\begin{tabular}{|c|c|c|c|c|c|c|}
\hline \multirow[b]{3}{*}{ Field } & \multirow[b]{3}{*}{ Region } & \multicolumn{4}{|c|}{ XRD } & \multirow{3}{*}{$\begin{array}{c}\text { Iron rich mineral } \\
\text { identify }\end{array}$} \\
\hline & & \multirow{2}{*}{$\begin{array}{c}\text { Total clay } \\
\text { whole rock } \\
\text { Average (mass } \\
\% \text { ) }\end{array}$} & \multicolumn{3}{|c|}{ Clay - whole rock (mass \%) } & \\
\hline & & & $\begin{array}{c}\text { Illite } \\
\text { Average }\end{array}$ & $\begin{array}{c}\text { Kaolinite } \\
\text { Average }\end{array}$ & $\begin{array}{l}\text { Chlorite } \\
\text { Average }\end{array}$ & \\
\hline $\mathrm{A}$ & Europe & 27 & 2.50 & $<1$ & 23 & Glauconite \\
\hline $\mathrm{B}$ & Central Europe & 14 & 1 & 10 & 4 & Chamosite \\
\hline $\mathrm{C}$ & Asia Pacific & 10 & 2.5 & 1 & 6 & Chamosite \\
\hline
\end{tabular}

\section{Sample characterisation by XRD, SEM and TSA}

Chlorite clays are phyllosilicates with the general chemical formula $(\mathrm{Mg}, \mathrm{Al}, \mathrm{Fe})_{12}\left[(\mathrm{Si}, \mathrm{Al})_{8} \mathrm{O}_{20}\right](\mathrm{OH})_{16}$. In sandstones, these tend to represent grain coating, pore lining and pore bridging phases which are most commonly observed as platy, fibrous/ bladed crystals (Ferich) or sometimes display a honeycomb structure (Mgrich). Chlorite clays are not considered to be particularly water sensitive but do have the ability, similar to illite, to retain water without swelling or potential fines migration. Chamosite is the iron rich $\left(\mathrm{F}^{2+}\right)$ member of the chlorite group.

Glauconite is a potassium iron phyllosilicate belonging to the mica mineral group with the following chemical composition $(\mathrm{K}, \mathrm{Ca}, \mathrm{Na})_{2}\left(\mathrm{Fe}^{3+}, \mathrm{Al}, \mathrm{Mg}, \mathrm{Fe}^{2+}\right)_{4}$, $\left[(\mathrm{SI}, \mathrm{Al})_{4} \mathrm{O}_{10}\right)_{2}(\mathrm{OH})_{4}$. It most commonly occurs as rounded pellets with an aggregated structure, flakes or as part of the rock matrix and can be confused with chlorite clays due to the similarity in colouration. The aggregated structure and internal geometry of this mineral gives it a high internal porosity which is not always connected to the main pore network. Where these are connected and depending on the exact composition and state of alteration, they can exhibit behaviour similar to some clay minerals such as smectite (associated with swelling) and are considered to be water sensitive.

X-ray diffraction (XRD) analyses, performed on end trims from the samples under study, show chlorite as the

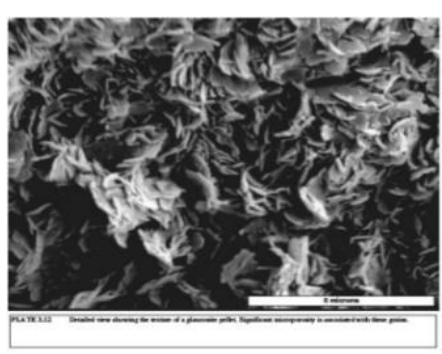

SEM - Glauconite detailed view showing the texture of glauconite pellets. most common clay among Fields A and C. For Field B the most recurrent clay (whole rock) is kaolinite followed by chlorite as presented in Table 4. Total clay content from Fields B and C is around 14\% or lower, for Field A, total clay content is around $27 \%$. High chlorite content is often associated with the presence of glauconite [14] and chamosite [15]; however, XRD data on its own does not allow the identification of the specific types of Fe-rich minerals.

Glauconite can be identified in a thin section (TSA) as it appears as round/oval peloids that are easily recognised by their bright green colour (Figure 6). However, in a black and white SEM image, glauconite appears as nondescript oval shape grains, as shown in Figure 7 Glauconite is difficult to identify without supplementary thin section and XRD analyses. Chlorite is clearly observed in Figure 8 (plate d) and then confirmed as glauconite grains by TSA as shown (plate e and f) in Field A samples.

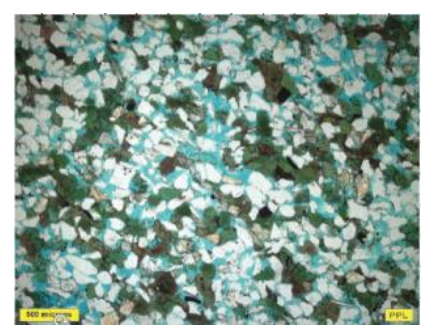

Fig. 6. Example of a TSA containing glauconite (bright green colour)

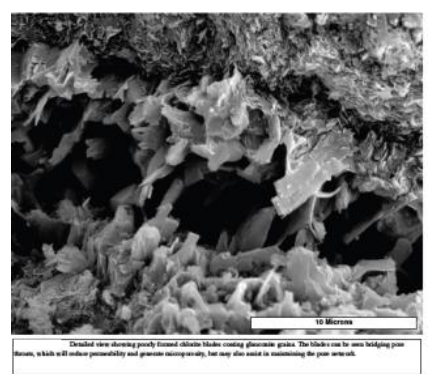

SEM - Glauconite detailed view showing poorly chlorite blades coating glauconite grains.

Fig. 7. SEM illustrations of glauconite pellets and glauconite with chlorite coating 


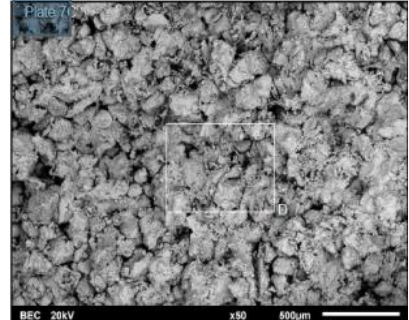

SEM - plate a

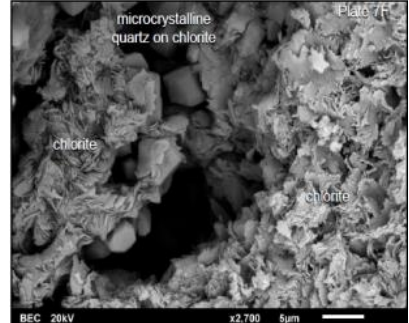

SEM -plate d

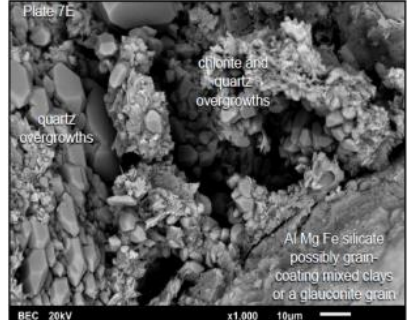

SEM - plate b

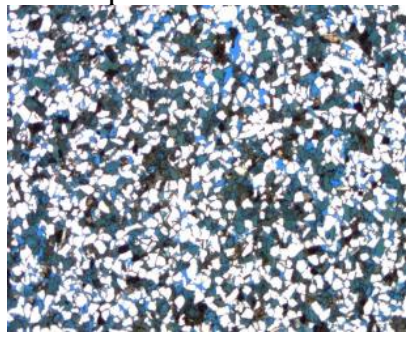

TSA -Glauconite plate e

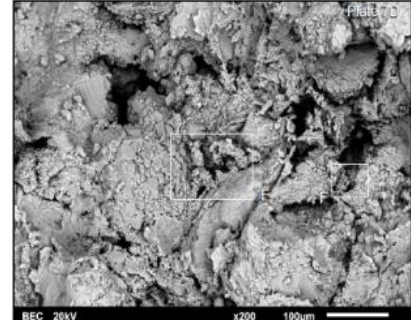

SEM -plate $\mathrm{c}$

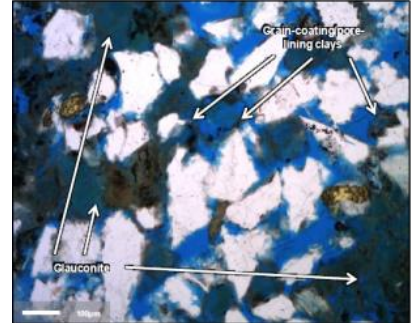

TSA - Glauconite plate $\mathrm{f}$

Fig. 8. SEM images (plate a to d) and thin section example (plate e and f) from Field A

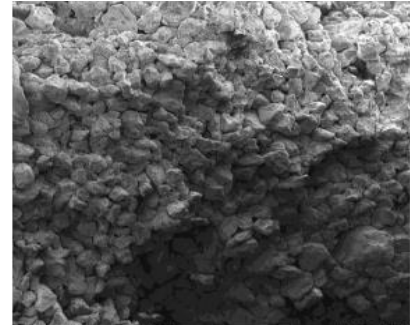

SEM - plate a

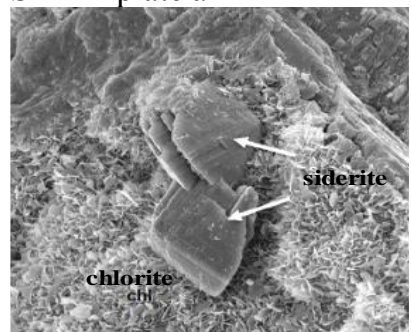

SEM plate d

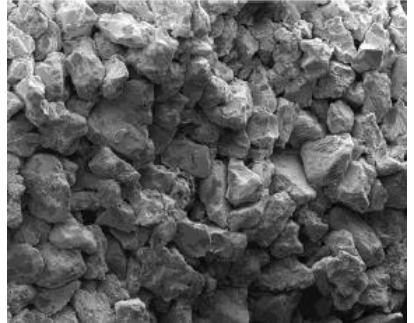

SEM - plate b

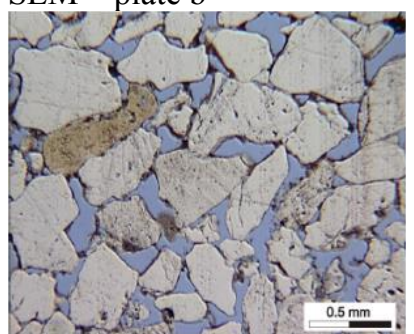

TSA - plate e

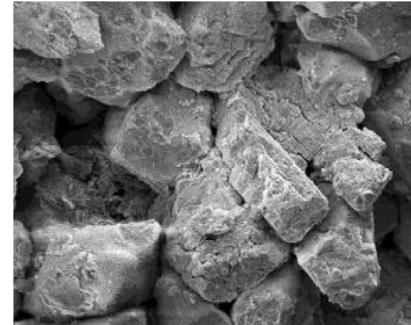

SEM plate $\mathrm{c}$

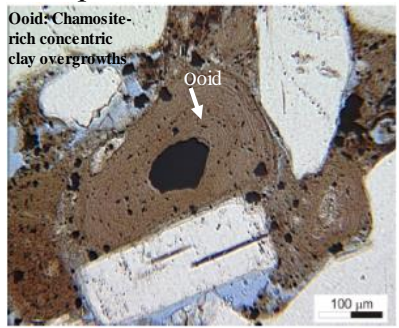

TSA - plate $\mathrm{f}$

Fig. 9. SEM images (plated a to d) and thin section images (plate e and plate f) showing chamosite identified as chamosite rich concentric clay overgrowths

Chamosite, on the other-hand, is identify by XRD and SEM energy dispersive X-ray spectroscopy (SEM-EDS). It can be seen as a green, grey-green or dark green coating on the grains in the thin section images (Fig. 9). SEM performed from Field B (Fig. 9) shows chlorite coating grains of quartz that were later identified as chamosite in the thin section image (plate e and $\mathrm{f}$ ). In a similar way, chamosite is identified in Fig. 10 on Field $\mathrm{C}$ samples. Chamosite coatings on wells from Fields $\mathrm{B}$ and $\mathrm{C}$ are not continuous and appear to be scattered on the petrography samples evaluated, which may explain the broad range of wettability indices obtained across the studied samples. An interpretation that combines XRD, SEM and TSA is required to identify glauconite and chamosite. 


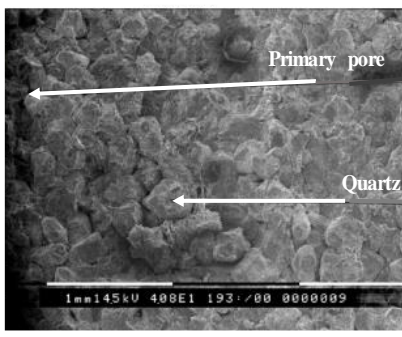

SEM - plate a

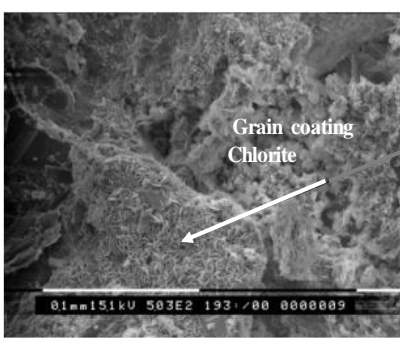

SEM - plate d

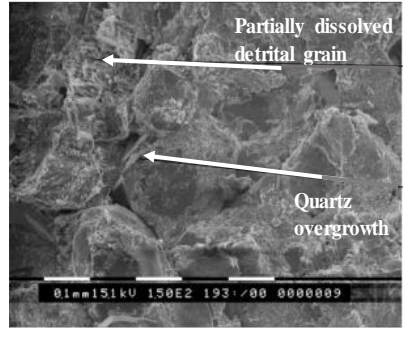

SEM plate $b$

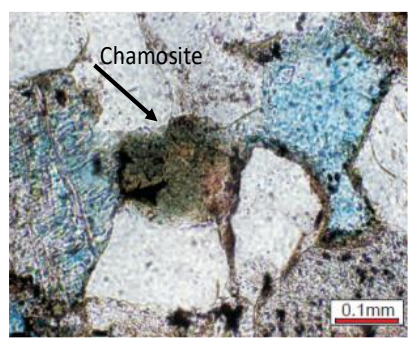

TSA - plate e

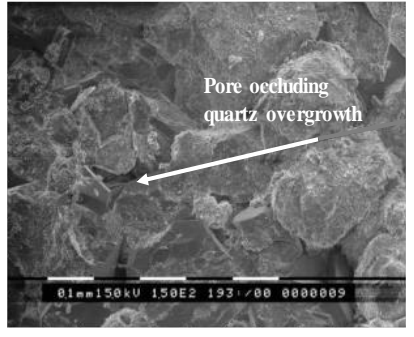

$\mathrm{SEM}$ - plate c

Fig. 10. SEM images (plates a to d) and thin section analysis (plate e) from Field C

\section{Results interpretation}

Field A samples exhibit a mixed wet condition for fresh state and restored state and a water wet condition for clean state samples, which indicates that even in the presence of glauconite, the cleaning process may have induced a water wet tendency. Ageing with crude oil induced a less water wet condition.

Wettability results for Field B show that the rock is oil wet regardless of state (clean, fresh or restored). This is counterintuitive, as it is normally expected that a standard sandstone formation will become more water wet following cleaning. Kaolinite content in Field B is the highest among the three fields, and this could contribute with the oil wet tendency in FS and RS samples of this field. However, the oil wetness of kaolinite reverts to water wet after cleaning. Thus, the oil wet tendency in clean state is believed to be caused by the presence of grain-coating chamosite, which has an affinity to oil inducing an oil wet rock even after fully cleaned of hydrocarbons. During the cleaning process, all the organic compounds adsorbed in the surface of the grains are thought to be entirely removed, leaving the clays exposed, in this case the pore lining chamosite coating. Iron ions (present in the chamosite) are known to bridge with clean quartz [2, 16, 17] providing positive sites for the adsorption of organic compounds within the synthetic oil.

Wettability tests on samples from Field $\mathrm{C}$ show a less oil wet tendency, than the samples from Field B. XRD of samples from Field $\mathrm{C}$ show a significant presence of illite, which are usually water wet after cleaning but can have significant impact on reservoir quality. This may have led to higher connate water saturation, hence, thicker water films and lower ability for oil to influence wetting tendency. Also, uncertainties in Field $\mathrm{C}$ coring fluid could have influenced the wettability. Thus, further investigation using mud tracers during coring and a full wettability study on fresh, clean and restored samples is recommended before a conclusion can be made.

It is likely that the degree of chamosite development (and/or presence) could lead to variance in wetting states, e.g. samples with poorly-developed chamosite coatings have less tendency to be oil wet than others.

\section{Conclusions}

USBM and Amott test results on three Fields two in Europe and one in Asia Pacific were consistent and showed a mixed to oil-wet tendency for fresh and restored state samples where chamosite was present. Some samples containing chamosite were also observed to be mixed to oil wet, even in clean state. Samples containing glauconite appeared to be water wet in clean state, and mixed wet either in fresh state or restored state.

The results suggest that the presence of both glauconite and chamosite was the main contributor to the oil wet tendency of the evaluated restored and fresh state samples, and chamosite for the clean state mixed to oil wetness. However, for Field $\mathrm{C}$ the possible used of additives in the WBM during coring and how this could have influenced the wettability tendency is still uncertain, thus further investigation is recommended.

Mineralogy has a significant role in wettability control, thus it is recommended that Field wettability studies include fresh state, clean state and restored state analysis as well as petrography: XRD, SEM and TSA on the tested sample end trims. Only by using these combined analyses can we begin to understand the wettability controls in each different Field. 


\section{References}

[1]. McPhee C., J. Reed, I. Zubizarreta, "Core Analysis: A Best Practice Guide" Petroleum Development in Science, 64 Series Editor J. Cubbit Elsevier 1st edition 2015.

[2]. Anderson G. A. "Wettability Literature SurveyPart 1: Rock/Oil/Bine Interactions and the Effects of Core handling on Wettability". SPE13932-PA 1986.

[3]. Anderson G. A. "Wettability Literature Survey Part 3: The effects of wettability on the electrical properties of porous media". J. Pet. Technol (1986), 38 (12), 1371-1379.

[4]. Anderson G. A. "Wettability Literature Survey Part 4: The Effects of wettability on capillary pressure." J. Pet Technol. (1987), Vol 39 (10), $1183-1300$.

[5] Anderson G.A. "Wettability Literature Survey Part 5: The Effects of wettability on relative permeability." J. Pet Technol. (1987), Vol 39 (11), $1183-1300$.

[6]. Jerauld, G.R. and J.J. Rathmell, "Wettability and relative permeability of Prudhoe Bay: a case study in mixed-wet reservoirs" In: Proceedings of 3rd International Symposium on Evaluation of Reservoir Wettability and Its Effect on Oil Recovery; Laramie, Wyoming. 1994

[7] Lebedeva E. A. Fodgen. T. Senden, M. Knackstedt, "Kaolinite Wettability - The Effect of Salinity, pH and Calcium" \# 11 in SCA, 2010.

[8] Bantignies J.L., C.C. Dit Moulin, H. Dexpert, "Wettability contrasts in kaolinite and illite clays: characterization by infrared and X-ray absorption spectroscopies. Clay Clay Miner.45 (1997), 2, 184-193.

[9] Fjelde I., A. V. Omekeh, P. E. Haugen, "Effect of Ferrous Ion $\mathrm{Fe}+2$ on Wettability: Oxidation and Cation Bridging" SPE -185816-MS 2017

[10] Kleinschmidt R. F. and P.B. Lorenz, "North Burbank Unit tertiary recovery pilot Test" BERC/TPR-76/ 2 Phillips Petroleum Company, Bartlesville, Oklahoma US. 1976

[11]. Trantham J.C. and R.L. Clampitt "Determination of Oil Saturation After Waterflooding in an OilWet Reservoir - The North Burbank Unit, Tract 97 project" SPE 58021977

[12]. Donanldson, E.C., R. D. Thomas, and P. B. Lorenz. "Wettability determination and its effect on recovery efficiency." SPEJ (1969), 9, 13-20

[13]. Fjelde, I., A.V. Omekeh, M.W. Minde, "Removal of Mud Components from Reservoir Sandstone Rocks" \#16 in SCA, 2015.

[14]. Thomas W. H., J.K. Ringen, S.O. Rash, "Effect of Glauconite on petrophysical properties as revealed by core analysis". \#32 in SCA, 2003

[15]. Brindley, G. W.; R.F. Youell, "Ferrous chamosite and ferric chamosite". The Mineralogical Society (1953) 30, 57-70

[16]. Morrow, N. R., H. T. Lim, J. S. Ward “Effect of Crude-Oil-Induced Wettability Changes on Oil Recovery", SPE-13215-IPA 1986

[17]. Zhang, G.Q, C.C. Huang, G.J. Hirasaki, "Interpretation of Wettability in Sandstones with NMR Analysis" \#9921 in SCA, 1999 